\title{
Performance Evaluation of Modified Bitumen Using EPS Beads for Green and Sustainable Development of Polymer-Based Asphalt Mixtures ${ }^{\dagger}$
}

\author{
Muhammad Kashif Anwar ${ }^{1}$, Syyed Adnan Raheel Shah 1,2,*, Muhammad Ahmed Qurashi ${ }^{1}$, \\ Muhammad Hasnain Saeed 1,2, Aqsa Nisar 1,2, Asfar Nasir Khan ${ }^{2,3}$ and Muhammad Waseem 4 \\ 1 Department of Civil Engineering, Pakistan Institute of Engineering and Technology, \\ Multan 66000, Pakistan; kashifanwar723@gmail.com (M.K.A.); 2kx5civil114@piet.edu.pk (M.A.Q.); \\ hasnainsaeed420@gmail.com (M.H.S.) \\ 2 Faculty of Engineering Sciences, Bridge-Academy of Research and Innovation (BARI), \\ Islamabad 44000, Pakistan; 2kx5civil140@piet.edu.pk \\ 3 Department of Civil Engineering, National University of Sciences and Technology, Risalpur Campus, \\ Risalpur 24080, Pakistan \\ 4 Bayreuth Centre for Ecology and Environmental Research, University of Bayreuth, \\ 95440 Bayreuth, Germany; muhammad.waseem@uni-bayreuth.de \\ * Correspondence: syyed.adnanraheelshah@uhasselt.be; Tel.: +92-300-791-4248 \\ + Presented at the First International Conference on "Green" Polymer Materials 2020, 5-25 November 2020; \\ Available online: https://sciforum.net/conference/CGPM2020.
}

Citation: Anwar, M.K.; Shah, S.A.R.; Qurashi, M.A.; Saeed, M.H.; Nisar

A.; Khan, A.N.; Waseem, M.

Performance Evaluation of Modified Bitumen Using EPS-Beads for Green and Sustainable Development of Polymer Based Asphalt Mixtures.

Proceedings 2021, 69, 36. https:// doi.org/10.3390/CGPM2020-07190

Published: 4 November 2020

Publisher's Note: MDPI stays neutral with regard to jurisdictional claims in published maps and institutional affiliations.

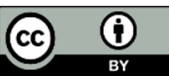

Copyright: $₫ 2020$ by the authors. Licensee MDPI, Basel, Switzerland. This article is an open access article distributed under the terms and conditions of the Creative Commons Attribution (CC BY) license (http://creativecommons.org/licenses/by/4.0/).

\begin{abstract}
The increasing costs of virgin content, decreasing resources, and growing plastic waste have shifted the research momentum towards green and sustainable road pavements. Hence, in recent years, various researchers have worked on the utilization of different types of plastic wastes in asphalt concrete by replacing it with binder content. Under this premise, this study examines the effect of expanded polystyrene beads (EPS) as a replacement to the binder at seven different dosages ranging from $5 \%$ to $50 \%$. The bitumen of $60 / 70$ grade was utilized in this study. The fresh properties of polymer-modified bitumen were checked and compared to that of conventional specimens. The mechanical properties of all specimens were investigated in terms of Marshall Stability properties. The results indicated that the adding of PEB improves the stability of modified asphalt concrete. Furthermore, the addition of EPS by substituting bitumen content could be a promising way to reduce the environmental impact of bitumen, and will also help in economic infrastructure development.
\end{abstract}

Keywords: sustainability; green and sustainable asphalt concrete; expanded polystyrene beads (EPS); mechanical properties; pavement

\section{Introduction}

Roads are among the most commonly used constructive elements that are using the highest tonnage of materials around the globe. About $91.9 \%$ of these roads are constructed in Europe with bituminous mixes, resulting in an increased demand for bitumen, a residue obtained after distillation of petroleum product [1]. The extraction and consumption of bitumen returns $0.048 \mathrm{~kg}$ of $\mathrm{CO}_{2} / \mathrm{kg}$ to the environment, a quite significant value, taking into consideration the need for 43.7 tons of bitumen for just $1 \mathrm{~km}$ of roadway, which indicates a carbon footprint of 2.13 tons [2]. The increased use of plastic materials aligns with this fact worldwide, because of their versatility and contribution to a massive quantity of plastic waste that is produced each year [1]. All this scrap, equivalent to $25.8 \mathrm{Mt} / \mathrm{year}$ in Europe, has been reused and renegotiated, as well as shifted near landfills [3]. The goal of conscientious countries is to reduce the amount delivered into landfills and to reuse such 
products, as well as reduce the use of virgin plastics [4]. Under these contexts, this research was established to study the potential replacement of bitumen with plastic waste to lessen the adverse effect of the former on the atmosphere. In this study, expanded polystyrene beads (EPS) were recommended and used as a modifier because of their thermoplastic behavior and low temperature of glass point [5]. They belong to a family of amorphous polymers, as well as most used polymers all over the world [3].

The additives can be mixed into a bituminous mixture in two ways: a wet process and a dry process. The process involves the earlier mixing of the emulsifier with bitumen as a modified binder for its later application. This method involves the crushing of the material that is to be used into very small sizes and carefully blending with heated bitumen to ensure proper homogenous mixing. The existing literature includes the utilization of polymers, such as end-of-life tires (ELTs), high-density polyethylene (HDPE), low-density polyethylene (LDPE), polymerizing vinyl chloride (PVC), polypropylene (PP), polyethylene terephthalate (PET), acrylonitrile butadiene styrene (PET), and silicon resin polymers [4,6-9]. In the case of dry mixing, the modifier is introduced and transferred to the mixer with aggregates and pure bitumen (unmodified). Hence, the bitumen is not directly modified by this method. The dry method makes it possible to apply high levels of supplements to the bitumen, which will contribute to making it more potentially cost-effective [10]. This method is much less evolved than the wet method, even with its technical advantages [11-13]. There are several investigations and studies relevant to the application of expanded polystyrene beads (EPS) in various areas that are available, such as buildings and structures, recycled polystyrene, geotechnics, acoustic emissions, or lightweight concrete [14-19].

This research has been designed to study the application of EPS as bitumen modified for the development of flexible pavement as a major replacement to binder content. This is for the sustainable utilization of waste material for the development of a polymer-based durable pavement.

\section{Materials and Methods}

\subsection{Experimental Framework}

The experimental work was conducted for the present study as summarized in the flow chart in Figure 1.

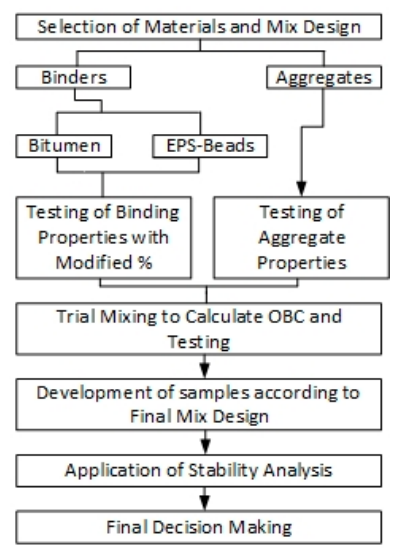

Figure 1. Flow chart of research methodology.

\subsubsection{Bitumen}

Bitumen with a penetration value of 60-70 was used in both modified (binder + EPS) and unmodified (pure binder) samples. Expanded polystyrene beads (EPS) was blended with pure bitumen. In this study, some basic tests of bitumen blended with EPS were per- 
formed, such as penetration, ductility, and softening temperature per the American Society for Testing and Materials (ASTM) standard. The basics tests of the pure binder are listed in Table 1 for comparative analysis of results using ASTM specifications [20].

Table 1. Basics tests of bitumen with their standards.

\begin{tabular}{cccc}
\hline Analyzed Properties & Units & Limit & Test Method \\
\hline Density at $25^{\circ} \mathrm{C}$ & $\mathrm{Kg} / \mathrm{m}^{3}$ & $1010-1060$ & ASTM D70 OR D3289 \\
Penetration at $25^{\circ} \mathrm{C}$ & $\mathrm{Mm} / 10$ & $60-70$ & ASTM D5 \\
Softening point & ${ }^{\circ} \mathrm{C}$ & $49-56$ & ASTM D36 \\
Ductility at $25^{\circ} \mathrm{C}$ & $\mathrm{Cm}$ & $100 \mathrm{~min}$ & ASTM D113 \\
Loss of heating & $\mathrm{Wt} \%$ & $0.2 \mathrm{max}$ & ASTM D6 \\
Flash Point & ${ }^{\circ} \mathrm{C}$ & $232 \mathrm{~min}$ & ASTM D92 \\
Solubility in Trichloroethylene & $\mathrm{Wt} \%$ & $99.0 \mathrm{~min}$ & ASTM D2042 \\
Viscosity at $60^{\circ} \mathrm{C}$ & $\mathrm{P}$ & $2000+/-400$ & ASTM D2171 \\
Viscosity at $135{ }^{\circ} \mathrm{C}$ & $\mathrm{cst}$ & $300 \mathrm{~min}$ & ASTM D2170 \\
\hline
\end{tabular}

\subsubsection{Aggregates}

In this study, an aggregate of sizes ranging from 10 to $20 \mathrm{~mm}$ was used for the preparation of modified and unmodified asphalt specimens. The performance characteristics of the aggregate used have been extensively tested in compliance with ASTM and BS standards [21], as presented in Table 2.

Table 2. Physical properties of the aggregate used.

\begin{tabular}{cccc}
\hline Type of Test & Test Methods & Result & Specifications \\
\hline Aggregate Impact Test & BS812: Part3 & $22.53 \%$ & Less than 27\% \\
Los Angeles Abrasion Test & ASTM: C131 & $28 \%$ & Less than 35\% \\
Aggregate Crushing Test & BS812: Part3 & $21.14 \%$ & Less than 30\% \\
Water Absorption Test & ASTM: C127 & $1.77 \%$ & Less than 2\% \\
Specific Gravity (Aggregate) & ASTM:C127 & 2.26 & 2 to 3 \\
\hline
\end{tabular}

\subsubsection{Expanded Polystyrene Beads (EPS Beads)}

Polystyrene $\left(\mathrm{C}_{8} \mathrm{H}_{8}\right)_{n}$ is also called polyvinyl resin. Polystyrene (PS) is an extended organic compound, and is widely used in food service industries. Structurally, it is linked with a phenyl array to each specific atom of carbon. Styrene is derived from the compound of polyvinyl resin by radical chemical reactions of vinyl [22]. Similarly, expandable polystyrene (EPS) is steam-heated styrene in raw beads, allowing it to expand [22]. It is widely used in many concrete applications, especially in the making of concrete blocks, as well as in geotechnical engineering, because it is light and cool $[14,23]$. It is a new type of additive that can be used in road construction because of its potential beneficial properties, i.e., adhesive properties and large surface area. The physical features [24] of EPS used during the research are shown in Table 3.

Table 3. Physical properties of EPS beads.

\begin{tabular}{cc}
\hline Physical Properties & Average Value \\
\hline Diameter & $2 \mathrm{~mm}$ to $5 \mathrm{~mm}$ \\
Adhesive bond strength & $0.165 \mathrm{MPa}$ \\
Density & $12 \mathrm{~kg} / \mathrm{m}^{3}$ \\
Softening point & $70^{\circ} \mathrm{C}$ \\
Ignition temperature & $285^{\circ} \mathrm{C}$ \\
Color & White \\
\hline
\end{tabular}




\subsection{Sample Preparation Process}

Expanded polystyrene beads were added to bitumen and replaced at five different dosages $(10 \%, 20 \%, 30 \%, 40 \%$, and $50 \%$ ) by the wet method. In this method, bitumen was heated first at $160-170{ }^{\circ} \mathrm{C}$, and then EPS was added into the hot bitumen, corresponding to each selected percentage by the weight of binder content. This substitution was done by removing the same quantity of bitumen by the weight of binder content in grams corresponding to each selected percentage substituted by EPS. Before the preparation of blended asphalt samples, trial samples were prepared with pure bitumen to find the optimum percentage of the binder that met the standard. The EPS materials were mixed with hot bitumen to make it homogenous.

The aggregates used were heated at a temperature of about 150 to $170{ }^{\circ} \mathrm{C}$. All of the ingredients were blended for almost four extra minutes. This method was chosen because it allows bitumen to be directly mixed with EPS and it allows a comparison of the results of both modified and unmodified core samples, effectively and in a precise way. The sieve analysis was performed for the mixed aggregate, as shown in Figure 2.

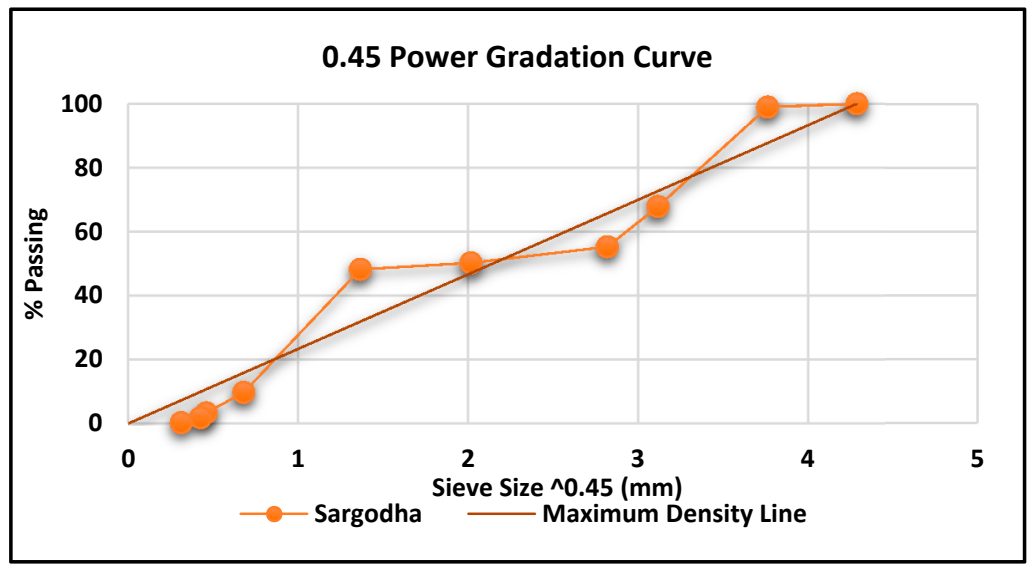

Figure 2. Gradation curve of the used aggregate for asphalt mixtures.

\section{Results and Discussions}

This research has been divided into two stages. In the first stage, all fresh properties of pure and EPS-modified bitumen were comprehensively analyzed for better comparative analysis of the results. In the second stage, Marshall stability analysis was performed for the EPS-modified mixture and was compared with control samples.

\subsection{Performance Analysis of EPS-Modified Bitumen}

In the first stage of the present study, all of the fresh properties of EPS-modified and pure bitumen were investigated for the study of comparative performance with reference to control samples to explore the effects of EPS. The EPS was introduced into hot bitumen up to $50 \%$ or partially by replacing bitumen content, respectively. Based on fresh results, it was concluded that the penetration value of modified bitumen decreased as the percentage of EPS increased when compared to pure bitumen of 60-70 grade. Similarly, the ductility value of modified bitumen was within limit with reference to the standard value $>75 \mathrm{~cm}$ up to $30 \%$ replacement; then, at $40 \%$ replacement, its value slightly decreased. The softening value of EPS-modified bitumen increased with an increase in the percentage of EPS content, which indicated that it could be the best option to used EPS-modified bitumen in hot climate conditions for the construction of flexible pavement. The results of EPS modification are presented along with the results of pure bitumen in Table 4 . 
Table 4. Physical properties of EPS-modified bitumen.

\begin{tabular}{ccccc}
\hline \multirow{2}{*}{ Sample } & \multirow{2}{*}{ Composition } & Penetration & Ductility & Softening Point \\
\cline { 2 - 5 } & (25 $\left.{ }^{\circ} \mathbf{C}, \mathbf{1 0 0} \mathbf{~ g}, \mathbf{5} \mathbf{~}\right)$ & $\mathbf{2 5}{ }^{\circ} \mathbf{C}$ & ${ }^{\circ} \mathbf{C}$ \\
\hline Test Method & ASTM: D5-97 & ASTM: D113 & ASTM: D36 \\
\hline Units & $0.1 \mathrm{~mm}$ & $0.1 \mathrm{~cm}$ & $1{ }^{\circ} \mathrm{C}$ \\
\hline M 1 & $100 \%$ B + 0\% M & 68.1 & 95 & 50 \\
M 2 & $90 \%$ B + 10\% M & 59.4 & 90 & 56 \\
M 3 & $80 \%$ B + 20\% M & 52.5 & 79 & 62 \\
M 4 & $70 \%$ B + 30\% M & 42.0 & 73 & 68 \\
M 5 & $60 \%$ B + 40\% M & 36.9 & 67 & 74 \\
M 6 & $50 \%$ B + 50\% M & 45.3 & 75 & 79 \\
Standard & Pure Bitumen & $60-70$ & $>75$ & $40-55$ \\
Remarks & & $>60$ are ok & $>75$ are ok & Higher than level \\
\hline
\end{tabular}

\subsection{Marshall Stability Analysis of EPS-Modified Mixtures}

The stability analysis was performed for comparative performance analysis of both modified and unmodified asphalt concrete. For this purpose, three samples on each percentage of EPS content were cast according to the standards, and then average values were taken for better results analysis. The results indicated that, with an increasing percentage of EPS content, the stability value increased up to $40 \%$ replacement, and afterward decreased. The optimum binder content (OBC) was $7 \%$. The increase in the stability value could be due to enhanced bonding properties between aggregate and modified bitumen (EPS\% + pure bitumen). Based on the stability analysis, it can be concluded that the addition of EPS up to $40 \%$ showed satisfactory performance compared to conventional asphalt mixtures. The relationship between the stability and flow values of modified asphalt concrete and EPS beads percentage is presented in the contour plot in Figure 3a. The darker regions in the contour plot in the form of a growing ridge surface show higher stability in the upper left to the middle of the graph. As the response increases, it appears darker.

It can be concluded that the flow value decreased with increasing EPS content up to $40 \%$ replacement. The flow value of the control specimen with an OBC of $7 \%$ was 3.95 $\mathrm{mm}$, which complies with the standard range $(2-4 \mathrm{~mm})$. It was observed in earlier studies that the flow value cannot give true reflection regarding the permanent deformation of flexible pavement. Therefore, to predict its behavior, further research studies need to be carried out on other tests, such as repeated load axial tests and wheel tracking tests, etc. The decrease in flow may be due to this reason: as the percentage of EPS increases, the bitumen becomes harder. In conclusion, the flow value tends to decrease with an increase in the percentage of EPS up to $40 \%$ in binder content.

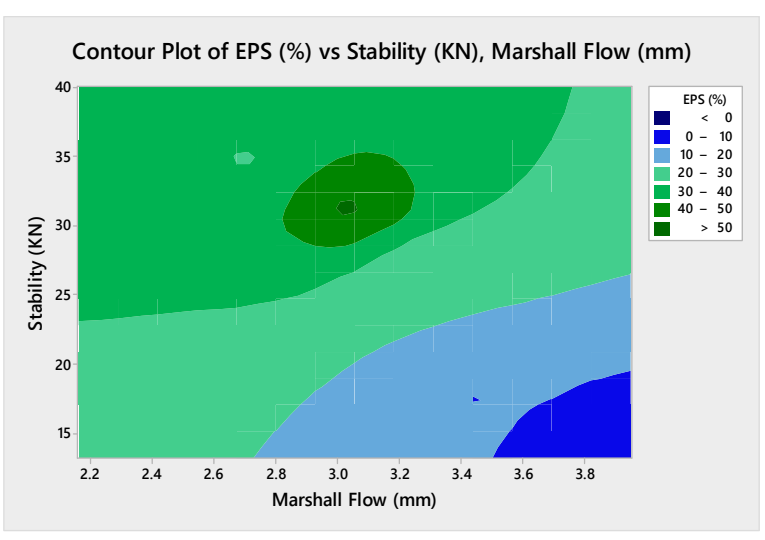

(a)

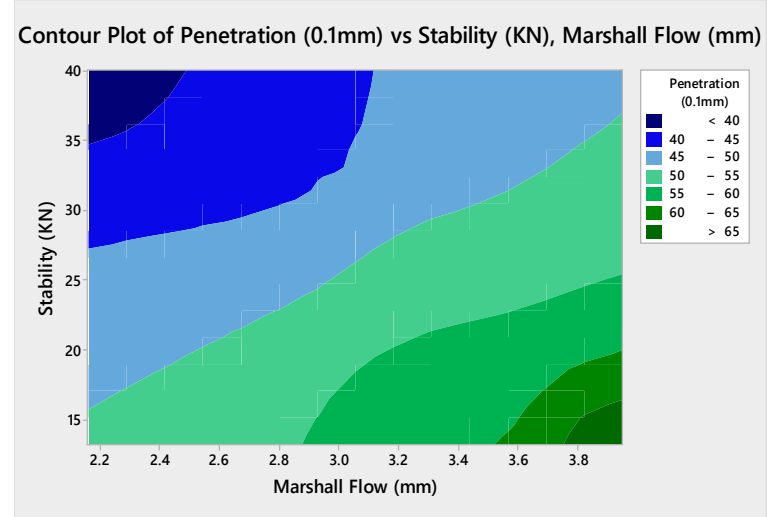

(b) 


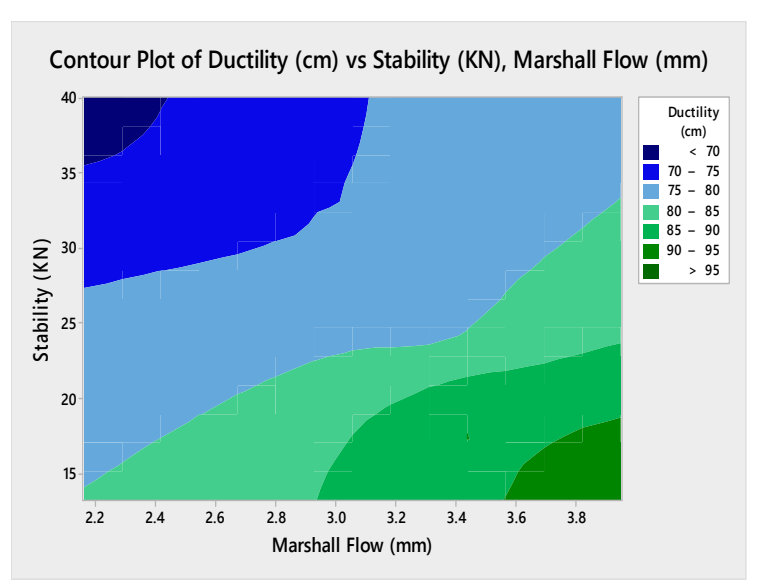

(c)

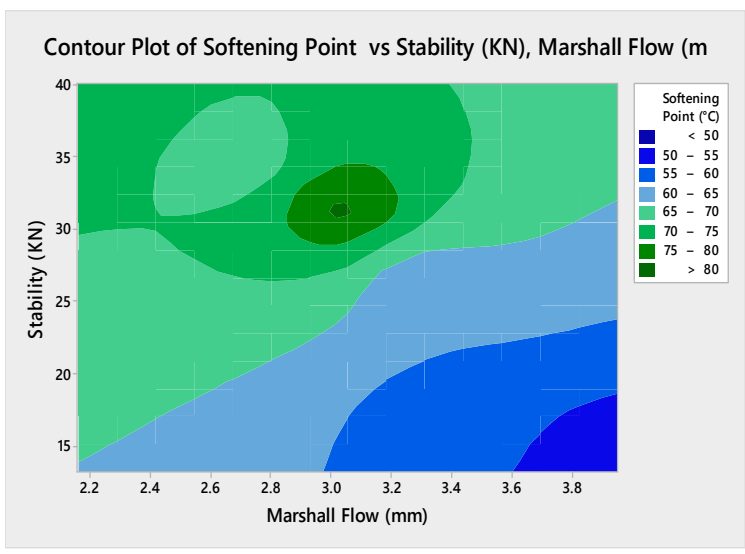

(d)

Figure 3. Comparative performance analysis for (a) EPS beads (\%) vs. stability (KN) and flow (mm); (b) penetration (0.1 $\mathrm{mm})$ vs. stability $(\mathrm{KN})$ and flow $(\mathrm{mm})$; (c) ductility $(\mathrm{cm})$ vs. stability $(\mathrm{KN})$ and flow $(\mathrm{mm})$; and $(\mathrm{d})$ softening point $(0.1 \mathrm{~mm})$ vs. stability $(\mathrm{KN})$ and flow $(\mathrm{mm})$.

The relationship between the stability and flow value is shown in Figure $3 b$, with results due to EPS beads content. In this plot, the higher penetration values are in a darker region in the lower right, which shows the relationship between stability and flow that results under high penetration values. Similarly, the relationship among both stability and flow and the ductility value of EPS-modified asphalt concrete can be seen in Figure 3c, which indicates that with an increase in ductility (response), the stability increases, but the flow will decrease at the same time. This relationship can be noted in the form of a ridge running from the upper left and lower right of the graph. Furthermore, the contour plot of the softening point against the stability and flow can be observed in Figure $3 \mathrm{~d}$. Observe the relationship between the surface outline, as well as the shape of the contours of the plot, which indicates that, as the softening point increases, the stability increases and flow value decreases at the same time. It can also be seen in the lower right corner of the contour map in the form of valleys. In conclusion, the stability values of EPS-modified bitumen increased due to an increase in their penetration and softening point, but this leads to a decrease in ductility and flow values.

\section{Conclusions}

The present study aimed to explore the potential benefits of the utilization of expanded polystyrene beads in road construction. Based on the experimental work, this study derived the following main conclusions:

- $\quad$ Based on results obtained from Marshall stability tests, the stability of asphalt concrete containing EPS was improved with varying percentages of EPS up to $40 \%$ replacement, but, afterward, a slight drop was observed in their stability values at $50 \%$ replacement.

- The flow values remained within a range of up to $40 \%$ with an increase in the EPS percentage, according to ASTM specifications. It is clearly shown that EPS increased the overall performance of asphalt concrete observed in the case of both fresh and mechanical properties. Higher values of softening points could be used in hot climate conditions in road construction, as they showed strong resistance against permanent deformation.

- It can be concluded that the use of EPS in road construction will offer a green, sustainable, and cheaper transport system. Furthermore, its effectiveness in terms of society and the environment are promising by reducing the demand for virgin bitumen.

Author Contributions: Conceptualization, M.K.A. and S.A.R.S.; Data curation, M.K.A., M.A.Q., and M.H.S.; Formal analysis, M.K.A., S.A.R.S., and A.N.; Investigation, M.K.A. and A.N.K.; Supervision, 
S.A.R.S.; Software, M.K.A. and S.A.R.S.; Writing-original draft, M.K.A. and S.A.R.S.; Writingreview and editing, M.W. All authors have read and agreed to the published version of the manuscript.

Conflicts of Interest: The authors declare no conflict of interest.

\section{References}

1. EAPA. European Asphalt Pavement Association. 2015. Available online: https://eapa.org/(accessed on July 18, 2020).

2. Hammond, G.P.; Jones, C.I. Embodied energy and carbon in construction materials. Proc. Inst. Civ. Eng. Energy 2008, 161, 87-98.

3. Leal Filho, W.; Saari, U.; Fedoruk, M.; Iital, A.; Moora, H.; Klöga, M.; Voronova, V. An overview of the problems posed by plastic products and the role of extended producer responsibility in Europe. J. Clean. Prod. 2019, 214, 550-558.

4. Punith, V.; Veeraragavan, A. Behavior of asphalt concrete mixtures with reclaimed polyethylene as additive. J. Mater. Civ. Eng. 2007, 19, 500-507.

5. Quinson, R.; Perez, J.; Rink, M.; Pavan, A. Yield criteria for amorphous glassy polymers. J. Mater. Sci. 1997, 32, $1371-1379$.

6. Attaelmanan, M.; Feng, C.P.; Al-Hadidy, A. Laboratory evaluation of HMA with high density polyethylene as a modifier. Constr. Build. Mater. 2011, 25, 2764-2770.

7. Vila-Cortavitarte, M.; Lastra-González, P.; Calzada-Pérez, M.Á.; Indacoechea-Vega, I. Analysis of the influence of using recycled polystyrene as a substitute for bitumen in the behaviour of asphalt concrete mixtures. J. Clean. Prod. 2018, 170, 1279-1287.

8. Yan, K.; You, L.; Wang, D. High-temperature performance of polymer-modified asphalt mixes: Preliminary evaluation of the usefulness of standard technical index in polymer-modified asphalt. Polymers 2019, 11, 1404.

9. Cui, P.; Wu, S.; Xu, H.; Lv, Y. Silicone Resin Polymer Used in Preventive Maintenance of Asphalt Mixture Based on Fog Seal. Polymers 2019, 11, 1814.

10. Desai, R.; Vora, N.; Dave, H. Use of plastic in bituminous concrete mixes. PARIPEX Indian J. Res. 2013,Vol.2, Issue.4. pp 176-180.

11. Lastra-González, P.; Calzada-Pérez, M.A.; Castro-Fresno, D.; Vega-Zamanillo, Á.; Indacoechea-Vega, I. Comparative analysis of the performance of asphalt concretes modified by dry way with polymeric waste. Constr. Build. Mater. 2016, 112, 1133-1140.

12. Mauskar, J. Performance Evaluation of Polymer Coates Bitumen Built Roads; Programme Objective Series, Probes/122/2008-2009; Ministery of Environment and Forest: New Delhi, India, 2008.

13. Shankar, A.; Koushik, K.; Sarang, G. Performance studies on bituminous concrete mixes using waste plastics. Highw. Res. J. 2013, $6,1-11$.

14. Gao, H.; Liu, J.; Liu, H. Geotechnical properties of EPS composite soil. Int. J. Geotech. Eng. 2011, 5, 69-77.

15. Garcia-Valles, M.; Avila, G.; Martinez, S.; Terradas, R.; Nogues, J.M. Acoustic barriers obtained from industrial wastes. Chemosphere 2008, 72, 1098-1102.

16. Gonzalez Madariaga, F.J.; Macia, J.L. EPS (expanded poliestyrene) recycled bends mixed with plaster or stucco, some applications in building industry. Inf. Construcción 2008, 60, 35-43.

17. Poletto, M.; Zeni, M.; Zattera, A.J. Dynamic mechanical analysis of recycled polystyrene composites reinforced with wood flour. J. Appl. Polym. Sci. 2012, 125, 935-942.

18. Vasudevan, R.; Sekar, A.R.C.; Sundarakannan, B.; Velkennedy, R. A technique to dispose waste plastics in an ecofriendly wayApplication in construction of flexible pavements. Constr. Build. Mater. 2012, 28, 311-320.

19. Barrasa, R.C.; Caballero, E.S.; Fresno, D.C.; Andrés, E.V.; Fernandez, M.N. POLYMIX: Polymeric waste in asphalt mixes. In M. Losa, \& T. Papagiannakis (Eds.), Sustainability, Eco-Efficiency and Conservation in Transportation Infrastructure Asset Management: Proceedings of the 3rd International Conference on Transportation Infrastructure, Pisa, Italy, 22-25 April 2014.

20. ASTM D946/D946M-20. Standard Specification for Penetration-Graded Asphalt Binder for Use in Pavement Construction; ASTM International: West Conshohocken, PA, USA, 2020.

21. Masad, E. Test Methods for Characterizing Aggregate Shape, Texture, and Angularity; Transportation Research Board: Washington, DC, USA, 2007; Volume 555.

22. Demirboga, R.; Kan, A. Thermal conductivity and shrinkage properties of modified waste polystyrene aggregate concretes. Constr. Build. Mater. 2012, 35, 730-734.

23. Qurashi, M.A.; Shah, S.A.R.; Farhan, M.; Taufiq, M.; Khalid, W.; Arshad, H.; Waseem, M.; Tayyab, M.; Shahzadi, G. Sustainable Design and Engineering: A Relationship Analysis between Digital Destructive and Non-Destructive Testing Process for Lightweight Concrete. Processes 2019, 7, 791.

24. ASTM-C: 78-06 Standard Specification for Rigid, Cellular Polystyrene Thermal Insulation; American Society for Testing and Materials: West Conshohocken, PA, USA, 2006. 